\title{
Los Consejos de Amalia a su hija Laura. Propaganda moral y construcciones genéricas en un texto escolar a comienzos del siglo XX en Argentina*
}

\author{
Adrián Cammarota*
}

\section{Resumen}

El trabajo analiza un texto escolar utilizado en las escuelas primarias a principios del siglo XX. El texto, que no fue único en su tipo, da cuenta de una serie de tópicos sostenidos asiduamente en las escuelas para firmar una supuesta naturaleza "femenina" y "masculina". Los Consejos delimitaban el rol de las niñas en la futura vida social, acorde con los preceptos que estructuraron la denominada teoría de la domesticidad. Consideramos que esta obra tenía como finalidad defender un supuesto legado natural. Este parecía peligrar ante los avatares del proceso de modernización por el cual atravesó la Argentina a fines del siglo XIX, con el crecimiento urbano y su ingreso en el mercado mundial.

\section{Palabras clave}

Texto escolar - pedagogía - genero - educación.

\section{Abstract}

The paper analyzes a textbook used in primary schools in the early twentieth century. The text, which was not unique in its kind, reveals a series of topics held regularly in schools to sign a

\footnotetext{
* Artículo recibido 26 de marzo de 2012. Aceptado 7 de diciembre de 2012.

** Magister en Historia (UNTREF). Doctorando en Ciencias Sociales, Universidad Nacional General Sarmiento - Instituto de Desarrollo Económico y Social (UNGS-IDES). Integrante del Proyecto UBACyT "Trabajo y salud en Argentina: saberes Académicos y Políticos (1915-1955) del grupo de investigación Historia y Prospectiva de la Universidad Latinoamericana HISULA, Universidad Pedagógica y Tecnológica de Colombia.
} 
so-called 'feminine' and 'masculine'. Tips delimited the role of girls in the future social life according to the precepts that structured the so-called theory of domesticity. We believe that this work was intended to defend an alleged natural legacy. The same seemed threatening to the vicissitudes of the modernization process by which Argentina went through in the late nineteenth century, with urban growth and its entry into the world market.

\section{Keywords}

Education - textbook - pedagogy - gender - education.

Una de las paradojas de la modernidad, bien definidas por Joan Scott, radica en que la Revolución Francesa proclamó la universalidad de los derechos del hombre generando un individuo abstracto sexualizado (el republicano burgués) (Scott, 1996). Su contracara se encarnó en la figura y en la suerte corrida por Olimpia de Gauges. El argumento de Scott puede definirse como una crítica a la modernidad. Paradójicamente, la noción de ciudadanía moderna ensamblada a partir de la revolución se sustentaba en la diferenciación genérica de los ciudadanos. Se invocó a la igualdad universal a partir de la construcción de la diferencia.

La teoría scottiana nos permite pensar el caso argentino desde diversos ámbitos en donde se entrecruzan las relaciones intergenéricas. Uno de ellos es el campo de la educación. A fines del siglo XIX, la invención de la Nación abrevó en un conjunto de tensiones que estaban implícitas en el proceso de secularización del Estado (Bertoni, 2001). Entre la Declaración de los Derechos del Hombre y del Ciudadano de 1789 a los derechos civiles y políticos proclamados en América Latina, existe un nexo interesante señalado por Scott para Francia: la segregación de la mujer de la vida social y política y la asignación de determinados mandatos basados en una supuesta naturaleza femenina. Sustancialmente, el denominado proceso de modernización acarreó en parte las contradicciones señaladas por Scott para la Revolución Francesa.

El análisis de los textos escolares no es novedoso en sí mismo. Ha sido abordado en diversos ángulos analíticos que van desde el sexismo en los libros de lectura a los intentos de politización de la educación (Wainermann y Barck de Raijman, 1987, Wainermann y Heredia, 1999, Plotkint, 1994). En este trabajo nos ocuparemos de encarar parte de los discursos que circulaban en el sistema de enseñanza primaria. Tomamos como objeto de análisis el libro de lectura para $6 .^{\circ}$ grado Consejos á mi hija. Lecturas de propaganda moral, de Amalia Palma. La obra fue aprobada por el Consejo Nacional de Educación en el año 1903 para las escuelas que se hallaban bajo su jurisdicción, las escuelas provinciales de Buenos Aires y de Córdoba, respectivamente. La elección de este material no es casual. Por un lado, consideramos que su formato 
discursivo, estructurado a modo de consejos, se diferenciaba del resto de los textos escolares de principios del siglo XX. Por el otro, este tipo de lectura no ha sido analizada en las investigaciones histórico-educativas que han inquirido en la temática esbozada. En otro nivel, vislumbramos que dicho texto tenía como finalidad contrarrestar las consecuencias nocivas del proceso de modernización que se inició en la Argentina finisecular. Este estuvo signado por el crecimiento urbano, el aumento de la inmigración, la protesta y la polarización social. Ese "nuevo mundo" amenazaba la constitución de un supuesto orden familiar, estructurado en una serie de preceptos tradicionales que hacían de la familia la célula básica de la sociedad. En definitiva, el planteo metodológico buscó relacionar la fuente descripta con el lugar culturalmente asignado a la mujer en ese contexto específico.

\section{Madres y maestras en la literatura pedagógica}

La Ley 1420 de enseñanza libre, gratuita y laica —aplicada en Capital Federal y Territorios Nacionales - estableció como contenidos obligatorios en las escuelas primarias las materias Urbanidad y Economía Doméstica. Ambas asignaturas convergían en el modelamiento de la experiencia femenina, en cuya gramática se expresaba el rol de la futura madre en la sociedad. Sobre este contexto, a principios del siglo XX, una amplia literatura de orden moral, pedagógica y de economía doméstica perseguía un mismo objetivo: instruir a las futuras madres en la denominada "ciencia del hogar". Según un manual de Higiene e Economía Doméstica del año 1912, los grados elementales de esta ciencia estribaban en los siguientes puntos: "orden y limpieza", "ventilación", "consejos higiénicos para niños", "muebles y utensillos", "poner la mesa para el almuerzo y para la comida" y "trabajos domésticos ligeros" (Atkinson, García y Sellén, 1912). Estos manuales tienen una marcada estructura funcional, ya que velan por la buena organización y optimización del funcionamiento del mundo hogareño.

Así las cosas, los Consejos no se especializan en las razones de la maternidad, sino en la acción social supuestamente inherente al sexo femenino. En palabras de la autora, se busca que la mujer adquiera la instrucción y "... la alta cultura intelectual compatible con sus deberes y obligaciones". Los recursos estilísticos utilizados en este tipo de obra transfiguran un lazo mucho más afectivo y cordial por oposición a los científicos manuales de academia como los de economía hogareña o higiene. A su vez, algunos de ellos estaban dedicados a la enseñanza de las artes más diversas, como el corte de pelo (Lanciano de Pujolar, 1882).

Es dable destacar que ser maestra en el imaginario social representaba la extensión hogareña del rol maternal. Como ha señalado Graciela Morgade, "La 'madre educadora por vocación' constituyó un nudo de sentido de fuerte adhesión social e institucional" 
(Morgade, 2007: 403). Determinados discursos médicos, políticos e institucionales maternalizaban a las mujeres con un sesgo biologicista. La práctica docente se había transformado en una suerte de extensión de las prácticas femeninas que por "natural" exigencia se les recomendaba el buen gobierno del hogar.

\section{Consejos de una madre-maestra a su hija adolescente}

Los Consejos de Amalia están dirigidos a su hija Laura, de catorce años. El fin es ilustrarla en los secretos de la maternidad y adiestrarla en el buen manejo de la economía hogareña. Sobre el origen del volumen, la autora destaca que surgió a raíz de la ausencia de un manual que eduque a las niñas en un "carácter genuinamente doméstico". Cabe aclarar que no pudimos rastrear la cantidad de ejemplares editorializados ni el nivel de circulación.

La obra se encuentra dividida en cuatro tomos, cuyo título genérico es "La Vida Práctica". El tomo 1, Consejos á mi hija, es el único de los cuatros volúmenes que aquí analizaremos, ya que no se encuentra disponible el resto de las ediciones. El libro dos, según describe la autora en el prefacio, trata de la organización material del hogar ("El hogar Modelo"). Por su parte, el tomo 3 se hace eco de la salud y la higiene; mientras que el último libro hace referencia a la "Higiene Alimenticia".

Recorriendo los derroteros del texto se puede observar una suerte de altruismo social que encorsetó el papel de las mujeres al definir un rol específico en la sociedad. Se hallaba secundado por los valores de la abnegación, el respeto sumiso al varón y el sacrificio despojado de cualquier tipo de actividad social o política. Pero los Consejos no son solo un compendio de reglas de moralidad. En el fondo de la cuestión, trasciende uno de los aspectos mencionados por Scott en cuanto a la construcción del género. Se puede visualizar una suerte de reduccionismo cultural, sustentado en un conjunto de conceptos normativos que le atribuía a la mujer un espacio de sumisión social en relación con el varón. Así editorializa Amalia esta cuestión:

"Tus gustos y comodidades personales, Laura, satisfácelos, después de los de tu esposo; depón toda egoísta satisfacción de tu bienestar en provecho del jefe de la familia y de los demás miembros de ella, y realiza esto sin ostentación, sin pedir gratitud ni aplauso, sin hacer valer lo que haces, porque no haciéndolo así, tus actos no probarán ninguna abnegación, sino un exceso de presunción" (Palma, 1903: 27).

La ética de la postergación femenina en beneficio del otro es clara y contundente en el párrafo citado. La matriz cultural que definía esa escala de valores implica un código de comportamiento transmitido en el seno del hogar. Esa formación que pretendía ser "objetiva", "natural" y "verdadera"; remitiendo a una actividad simbólica, estaba 
ordenada jerárquicamente. Es dable señalar que la relación entre los sexos se construyó de este modo, siendo una "parte crucial de la organización de la igualdad o desigualdad" (Scott, 1996: 71). A modo de ejemplo diremos que a principios del siglo XX las mujeres carecían de derechos civiles, políticos y sociales debido al "sexo". La situación reseñada se hallaba entroncada a una supuesta necesidad de tutela ejercida por el varón (el padre, el hermano, el marido). La finalidad era asegurar la transmisión de bienes a los herederos legítimos para la preservación del "honor" de la familia patriarcal.

\section{Cuerpos, modelos y consejos}

En el mapa genético del sistema escolar de principios del siglo XX los impulsos homogeneizantes atentaban, paradójicamente, contra las nociones que creían defender al invocar el discurso universalista. La identidad nacional se constituyó sobre la base de la diferencia y no sobre los parámetros de la inclusión. La pedagogía normalista sustentó las clasificaciones y las jerarquizaciones de los alumnos/as. Según Inés Dussel, esta pedagogía tomó el molde biologicista y se medicalizó velozmente. Los que se desviaban de esta norma eran clasificados como anormales (Dussel, 2000: 12). Sobre este horizontes de aspiraciones se intrincaron los dispositivos de vigilancia expresados en el vestuario escolar, la distribución de tiempo y espacio y la modelación de los cuerpos con la imposición de una cultura somática específica.

Hay que subrayar que el cuerpo es el referente primario de la identidad sexual. A partir de él se fabrican los contenidos, roles y comportamientos que se estratifican en imágenes socioculturales (López y Vélez, 2001: 97). Desde sus orígenes, el sistema de enseñanza vernáculo se modeló binariamente. Las niñas eran educadas en las nociones básicas de economía doméstica, mientras que los varones eran adiestrados en el conocimiento de los ejercicios militares. El rol de las niñas estaba definido en términos de su función sexual y procreativa. Este proceso de naturalización de la masculinidad y feminidad se apoyó en un saber fisiológico cuyo discurso promovía las desigualdades de género (Scharagrodsky, 2006: 111-112). En consecuencia, la cultura escolar reforzaba los mandatos de género afincados en los criterios de normalidad del cuerpo social.

Acorde con los marcos normativos de la época la sexualidad se hallaba ausente en los manuales escolares y por ende, en la narrativa de los Consejos. El cuerpo femenino dormitaba entre el encorsetamiento curricular, los dolores menstruales y la ausencia de información en torno a la sexualidad en el currículum escolar. La situación descripta bien podría haber sido añadida a una de las paradojas observadas por Joan Scott para la Revolución Francesa: mientras que la escuela sostenía una cultura "humanística y científica", cimentada en los preceptos del positivismo decimonónico, se censuraron 
determinados conocimientos para la parcial sumisión de la identidad corporal femenina. A modo de ejemplo podemos subrayar que los planes de estudio hacían referencia, en líneas generales, al modelo médico-biologicista centrado en un reconocimiento general del cuerpo. A ello hay que adjuntar las prerrogativas doctrinarias de una cultura católica que actuaba como muro de contención a las inquietudes corporales de niños/as y adolescentes, formando así una argamasa de orden moral. En este escenario, ante la nula capacidad de las escuelas para abordar los vaivenes del cuerpo femenino, la información circulaba por otros canales más informales: entre mujeres, madres, hijas, vecinas, se transmitían un conjunto de prácticas, conocimientos y experiencias vinculados con los cuerpos y la reproducción (Nari, 2005: 109).

Ahora bien, la modelación del cuerpo femenino se instituyó por medio de la autoridad del varón en una especie de "microestado" representado por el hogar. La autoridad patriarcal era un privilegio que él detentó gracias a un conjunto de supuestas cualidades innatas, como la fortaleza muscular, el vigor y la destreza. Esas cualidades se empeña en enseñar Amalia a su hija adolescente. Podemos agregar que la justificación del patriarcado tiene como base una fundamentación de orden ideológico sustentada en una supuesta debilidad e inferioridad del sexo femenino. En este sentido, los Consejos expresaban el grado de influencia de las teorías científicas esbozadas a fines del siglo XIX en el viejo continente. Aquellas insinuaron una serie de juicios valorativos con un sesgo sexista y racista signada, a su vez, por nociones que estimulaban una mirada social androcéntrica y misógina. La fisiología, la anatomía, la neurología, la antropología física y la psicología se encargaron de enfatizar las diferencias de ambos sexos. Spencer compartió la idea de la inferioridad mental de las mujeres, asimilándolas con la naturaleza de las bestias. Sobre esta carga de sentidos, el déficit intelectual y moral las alejaba punitivamente de la esfera pública otorgándoles el mandato del hogar. Dichos enfoques redujeron el cuerpo femenino a la definición específica de una relación social medular entre hombres y mujeres (Gómez Rodríguez, 2005). Se tomaba como un parámetro cuyo envés sociológico terminaba reduciendo lo femenino, por oposición a lo masculino, a la debilidad, el dolor y el sacrificio. Como ha destacado Marcela Nari, la abnegación, el altruismo y el sufrimiento signaron la relación de las mujeres con sus cuerpos castigados por los dolores de origen biológico, ya sea la menstruación, la menopausia o los dolores inminentes del parto (Nari, 2005: 108-109). En consecuencia, las mujeres se dedicaban a ser madres, maestras o participaban en la asistencia o la beneficencia social, como veremos a continuación. 


\section{La asistencia social o la caridad}

Apelando al ejercicio de la civilidad de la tradición judeo-cristiana, la madre aconseja practicar la caridad por medio de un "sistema racional de actos de beneficencia" (capítulo VI). La caridad correspondía ser ejercitada con cierto cuidado: "lo mismo que los hombres, es algunas veces ciega y á menuda [sic] descaminada" (Palma, 1903: p. 65). Debía estar sometida al imperio de la razón para evitar "mantener las lepras sociales" y encarrilarse en la ardua tarea de reconocer "al pobre falsificado". Nuevamente el espacio urbano modelado en torno de las prácticas e imaginarios de la nociva modernidad se contrapone a la "pureza "tradicional del ámbito rural. En los grandes centros de población" se torna más difícil identificar a los especuladores que viven de la caridad. El sostenimiento de las sociedades filantrópicas, por medio de una cuota en dinero, es una de las opciones barajadas por la autora para paliar los efectos negativos de la pobreza, alterado por los avatares de una ciudad impura caracterizada por las enfermedades, la prostitución, el alcoholismo y la pobreza por oposición a la opulencia de la oligarquía gobernante.

¿Cómo discernir entre los verdaderos marginados de aquellos advenedizos que se aprovechan de la buena voluntad del ciudadano? La respuesta es sencilla. La madre recomienda a su hija tener sus "propios pobres" y brindarles ayuda hasta que las causas de sus desdichas hayan desaparecido estimulándolos, a su vez, "... á emprender algún trabajo al alcance de sus fuerzas...". De lo contrario, si el excluido no acepta de buena gana los consejos brindados es "porqué encuentra más agradable mendigar que trabajar, y entonces, ese mendigo, por su gusto no merece tus simpatías..." (Palma, 1903: 66). Se genera así una suerte de clasificación social sustentada en la buena o mala disposición del individuo para afrontar las desdichas sociales. Aquí se despliega uno de los puntales del ideario liberal. Las decisiones individuales son las que determinan el destino. Desde esta óptica, el texto anula las responsabilidades sociales que caracterizan las dinámicas distributivas del modo de producción capitalista.

Pero existe una clase de pobres que son "dignísimos de compasión": las pobres vergonzantes (el subrayado es de la autora). Son aquellas mujeres viudas que han quedado sin recursos y no poseen ningún conocimiento de arte o industria para hacerse de un sustento. En este aspecto la caridad se reduce a la transmisión de los conocimientos necesarios para elaborar trabajos manuales.

La lucha por la existencia de las mujeres desamparadas o viudas constituye una de las preocupaciones más acuciantes de Amalia. A principios del siglo XX el trabajo de las mujeres, mal remunerado y prácticamente sin ningún tipo de legislación que protegiera su integridad, fue motivo de debate por los distintos actores de la esfera política (Lobato: 2007). De esta forma el texto señala una tensión en cuanto a que 
"Se exige virtud absoluta a las mujeres, se les confía la custodia del honor de la familia, y al mismo tiempo se las abandona á todos los embates morales y materiales sin preocuparles de darles el bien templado escudo del trabajo honorable y fructífero para que con él atajen los avances de la miseria y ahuyenten el demonio de la seducción, enemigos formidables que acechan constantemente" (Palma, 1903: 85).

Huelga decir que el desarrollo industrial en la Argentina avanzó sobre la producción casera creando un proletariado industrial. La producción estandarizada de las grandes fábricas convirtió a las mujeres en potenciales trabajadoras en el ámbito urbano. El trabajo femenino acaparó copiosas críticas tanto de los sectores de izquierda como del catolicismo. Para los sectores más conservadores, las fábricas apartaban a las mujeres de la atmósfera del hogar (Rocchi, 2000: 224). A pesar de ello, el trabajo femenino asalariado era considerado un hecho excepcional, solo soportado en situaciones puntuales como el abandono masculino, ingresos paternos o maritales insuficientes o estado de viudez. Esta situación se afianzaba en la idea de complementariedad, es decir, la labor femenina necesaria para reforzar los ingresos del varón proveedor. Muchas de las mujeres que no se vieron interpeladas en la necesidad de ingresar en el mercado laboral finalizaron sus estudios primarios e ingresaron como empleadas administrativas (Queirolo, 2008: 132). Sin embargo, ante esta afirmación hay que señalar que el número de mujeres inscriptas en la carrera de medicina radicada en la Universidad de Buenos Aires durante la primera mitad del siglo XX tuvo un incremento destacado. Las mujeres que lograron obtener su credencial académica para desempeñarse en el ámbito de la medicina intentaron llegar a cargos a los cuales no habían podido acceder hasta entonces debido a las jerarquías genéricas que las invisibilizaban. Algunas de ellas, como Alicia Moreau de Justo, unieron el saber específico del campo profesional con la discusión que irradiaba de la cuestión social (Valobra y Ramacciotti, 2011).

En efecto, este proceso estuvo entroncado con las aspiraciones inherentes del creciente sistema capitalista que generó una nueva configuración social en los grandes centros urbanos como Buenos Aires trazando, respectivamente, una fuerte polarización social. Sobre este escenario, el modelo de mujer "civilizada" se contraponía al de las mujeres o niñas "proletarizadas", vilipendiadas en las fábricas de la gran urbe. En su mayoría eran niñas recién llegadas a la pubertad. Los consultorios médicos fueron testigos ineludibles de esa realidad. Por allí desfilaron las jóvenes obreras anémicas, con sus cuerpos alterados y sus funciones fisiológicas maltratadas por la avaricia del "gran capital". En los Consejos prácticamente no se cuestiona las causas de esa realidad o del orden social imperante. Menos aun se menciona el incipiente papel de las mujeres en los conflictos gremiales de principios del siglo XX o su participación en 
organizaciones sindicales femeninas impulsadas por los socialistas (Lobato, 2000: 248251).

Para Amalia, esa realidad circundante constituía un escenario periférico del cual su hija debía estar alejada. La fábrica es visualizada como un eje de inmoralidad. Al respecto, Mirta Lobato ha señalado que el trabajo femenino en el taller o en la fábrica atentaba contra el honor y la reputación de las mujeres. Jefes y capataces, incluso sus propios compañeros, podían empujarlas al "pecado", cayendo en la tentación de una relación amorosa que esquivara el mandato del matrimonio (Lobato, 2007: 95) o, en el peor de los casos, ser presa del abuso sexual. Por último, los únicos puertos de refugio laboral para ellas son cuestionados en los Consejos: tareas como la costura, el bordado o el profesorado, según Amalia, son labores "mal retribuidos, al que se dedican muchas [mujeres] sin vocación".

\section{Teoría de la domesticidad y modernización}

La justificación de la teoría de la domesticidad se instruyó como la contracara de los avatares de la modernidad. Los aspectos decadentes del proceso de modernización debían ser corregidos desde todos los ángulos posibles. Las demandas de la sociedad civil para la ampliación de la ciudadanía política — corporizada en la ley Sáenz Peña, de 1912 - fueron una de las reformas impulsadas por el Estado. Si bien la ley establecía que el voto sería "secreto, universal y obligatorio", las mujeres quedaban exceptuadas del derecho al sufragio. Los fundamentos para esta segregación continuaban siendo de orden cultural, aunque se maquillaban con un manto de estatus jurídico. Como estimaban los manuales de Instrucción Cívica distribuidos en las escuelas "comunes de la República", para poder votar todo ciudadano debía estar inscripto en el padrón electoral formado, a su vez, del registro del enrolamiento (Guerrini, 1918 [1898]: 44-45). Los maestros y maestras desarrollarían la inteligencia y la moral de los futuros ciudadanos inculcando el cumplimiento de las leyes, el pago de impuestos y contribuciones y el cumplimiento del servicio militar. La vida del niño en el ámbito escolar se complementaba con el ejercicio de la moral política (Lionetti, 2005: 13).

Scott ha señalado que el género se define como un "elemento constitutivo de las relaciones sociales" entroncándose con una construcción subjetiva sobre el otro sexualizado. Esta construcción, desde la perspectiva de Amalia, implica la diferenciación jurídica, es decir, la ausencia de derechos políticos. La desigualdad genérica es consumada en un plano biológico. La mujer poseía una "debilidad cerebral" que indicaba una inteligencia menor que la masculina. Esto justificaba su segregación de la práctica política: 
"... porque él [hombre] siempre fue el más vigoroso, el más razonador, de más capacidad, el mejor preparado; aunque la condición intelectual y la aptitud para el trabajo lleguen a modificarse beneficiosamente en la mujer, el hombre habrá de continuar siendo 'la cabeza de la mujer' como proclamó San Pablo" (Palma, 1903: 18-19).

En el universo narrativo de los Consejos las aspiraciones femeninas descentradas del foco doméstico resultan adrede soslayadas. Los mandatos de género sostenidos por el incipiente sistema escolar de aquel entonces no coagulaban posiciones progresistas como las sostenidas por las militantes feministas. Al compás de los cambios políticos operados bajo el régimen oligárquico, como la Ley Sáenz Peña, el feminismo empezó a despuntar ligado a la actuación de las mujeres en los partidos políticos. A fines del siglo XIX la Unión Cívica Radical (UCR) y el Partido Socialista Argentino (PSA) bregaron por la formulación de un nuevo estatuto de la ciudadanía. En estas plataformas políticas las mujeres profesaron sus primeros pasos en la militancia partidaria. Los incipientes actos de organización femenina y el sufragismo en la esfera pública se vislumbraron en el Primer Congreso Feminista Internacional (1910), impulsado por la Asociación de Mujeres Universitarias. Paralelamente se organizaba el Primer Congreso Patriótico de Señoras, quienes plasmaron una propuesta más conservadora (Valobra, 2008).

Sujeta a una cosmovisión netamente cultural, la madre arguye:

"Te aconsejo, si quieres no se altere por tu causa la paz del hogar, no provoques discusiones contrariando las órdenes de tu esposo, no lo desafíes con un 'los dos somos iguales' ni menos pretendas que tu voto y tu voz vayan más allá de las suyas; acostúmbrate, cuando su voluntad esté en acción á reducir la tuya á la pasividad, más claramente que cuando él mande te quedes tranquila, sin pretender por la imposición desbaratar sus proyectos: si vieras que la suya fuera una orden irreflexiva ó que puede ocasionar perjuicios, entonces, sin reproches ni ironías, sin testigos, con suave tono, juiciosamente, convéncelo de que no es justo, no es bueno ó no es factible lo que se le ha ocurrido" (Palma, 1903:19).

Asociados a esta razón que raya entre la restricción política y el dominio varonil, los Consejos se sitúan en un marco dicotómico entre civilización (orden) o caos (carencia de civilidad doméstica, desunión). Los deberes de la urbanidad doméstica regulan una imaginaria armonía social, destierran las incertidumbres y la precariedad de una existencia que, sin la reproducción de determinados valores, parecería sucumbir ante las novedades del consumo y el hedonismo ("los hogares unidos son los que prosperan, porque en ellos hay orden, laboriosidad..."). El modelo de mujer civilizada, cultivado por la autora, está representado en la "buena ama de casa" con un "acabado 
de mujer culta y bondadosa" (Palma, 1903:43 y 45). Indudablemente, los Consejos remiten a la defensa de un legado natural que pareciera peligrar ante la sumisión de los preceptos de la modernidad: explotación del trabajo, promiscuidad y expansión de las enfermedades venéreas que degeneraban la raza y debilitaban la esencia de la nacionalidad argentina. En sintonía con estas aseveraciones, en la década de 1920 se dictaron una serie de leyes que tendían al control social: la ley de "Higiene Sexual Prematrimonial" (1924), de "Defensa de la Raza", (1925) y la ley que prohibía el matrimonio entre leprosos (1926).

\section{La formación intelectual de la mujer}

Otro de los tópicos que emerge del texto es el que se refiere a la educación intelectual de la mujer (capítulo VIII). La instrucción femenina no debía buscar otro objetivo que "hacer más perfecta a la familia" y por ende, "más feliz". En consecuencia las lecturas debían desarrollar la inteligencia y a la vez proyectarse sobre un objetivo primordial: fortalecer el sentido moral de la mujer. Dichas lecturas estarían tuteladas por personas de "honorable y de reconocido buen criterio moral". Rechaza de plano las modernas novelas literarias por ser poseedoras de un germen destructivo que envenena las "buenas costumbres" y "la pureza del pensamiento" y "excitan precoces pasiones", engendrando "frivolidad", "ligereza" y "el fastidio por la prosa de la vida" (Palma, 1903: 79).

Se recomienda no abusar de las novelas en cuanto a lectura se refiere, ya que proyectan una idea incierta de la vida y de los sentimientos humanos. El peligro que atañen estas obras para las ávidas lectoras radicaba en que:

“(...) concluye por perder la franca alegría, inseparable en quien no conoce aún el lado amargo de la existencia; tristeza incubada por los ideales irrealizables que esas lecturas forjan en su mente inexperta; así se la vé vagar, melancólica y abstraída, como desterrada de un mundo inmaterial, en pos de mujeres y de hombres modelados en los héroes ó heroínas de los romances que han llenado de fantasías su débil cabeza" (Palma, 1903: 80).

¿Cuáles son las lecturas recomendadas por Amalia? Específicamente aquellas que hacen referencia al honor, la virtud y las que inspiran actos virtuosos o un sentimiento nacionalista, traducidas en el género histórico y las biografías de los héroes que forjaron la Patria y la epopeya sudamericana. Vemos aquí la influencia de la corriente pedagógica normalista que modeló las prácticas de las maestras. Uno de sus pilares ideológicos se estructuraba en la enseñanza de los arquetipos humanos y las vidas ejemplares. Los símbolos de la pedagogía ejemplar se materializaban en el hombre 
santo, el filósofo, el educador, el sabio, el caballero, el artista y el soldado. Estas reflexiones confluían en el aula, en la vida cotidiana de docentes y escolares (Gagliano, 2003: 176-180). Siguiendo a la investigadora Adriana Puiggrós, la pedagogía normalista alentaba determinada conducta "normal" prescribiendo la "transgresión" o la "desviación", siendo uno de sus objetivos "homogeneizar" al inmigrante (Puiggrós, 1990: 41-42). Desde fines del siglo XIX, el Estado Argentino, por intermedio de la escuela, se preocupó por inculcar un conjunto de valores asociados a la Patria, la Nación y una ontológica moral cívica. Los distintos rituales escolares, como izar la bandera, conmemorar las fechas patrias, desfilar, tomar distancia y utilizar el guardapolvo blanco, contribuyeron a la definición ideológica de ese patriotismo. Gracias a las lecturas recomendadas, Amalia brega por abonar una normalidad específica para modelar las aspiraciones espirituales de las adolescentes unidas a un sentido instrumental en el manejo del hogar.

Las lecturas que poseen un sentido instrumental están sintonizadas en la obra del sociólogo Samuel Smiles, cuyos tomos se titulan El Carácter, El Ahorro, El Deber, La Ayuda Propia. Otras lecturas sugeridas son las biografías de hombres y mujeres "benefactoras de la humanidad", diarios o memorias de celebridades y tratados de Medicina Doméstica para responder a las "ligeras indisposiciones".

Las nociones de fisiología aprendidas en la escuela debían ser profundizadas para formar en el hogar niños y niñas más sanos. Según Amalia, si se ignoran estas leyes, las mujeres estarán expuestas a cometer todo tipo de sufrimiento en los infantes provocándoles, en diversas ocasiones, la muerte segura. La espantosa mortalidad infantil en las grandes ciudades modernas es atribuida por Amalia a los escasos conocimientos que tanto hombres como mujeres poseen "de las leyes del modo de vivir sano" (Palma, 1903: 83). Nuevamente se soslaya la dinámica desigual del creciente capital. Las acciones individuales, carentes de civilidad, encumbradas en un manto de ignorancia, son las promotoras de las desigualdades y de la muerte de los infantes. Desde su postura conservadora la autora remite a uno de los tópicos más relucientes del discurso higienista. Sin embargo, esto no constituía un enrolamiento de ideas patrimonio de la derecha política o de la Iglesia Católica. El Partido Socialista promocionó la higiene, la salubridad y la vivienda como ejes fundamentales en la vida de la familia proletaria. La Sociedad Luz —fundada por Juan B. Justo en 1899 para difundir la cultura en la masa obrera - se constituyó en uno de los focos irradiadores de saberes relacionados con la profilaxis, la higiene y la salubridad (Barrancos 1996: 120-121).

En síntesis, la obra presentada resume una de las paradojas de la modernidad. El modelo de mujer "civilizada" y "ciudadana" se instruía de los sabios conocimientos para el óptimo manejo del hogar, menos por las cuestiones de la "cosa pública". Ese "legado natural", sustentado en determinados símbolos normativos, apelaba a sostener y 
regular una supuesta armonía social reproduciendo, a su vez, las jerarquías sociales tradicionales que reforzaban los mandatos de género.

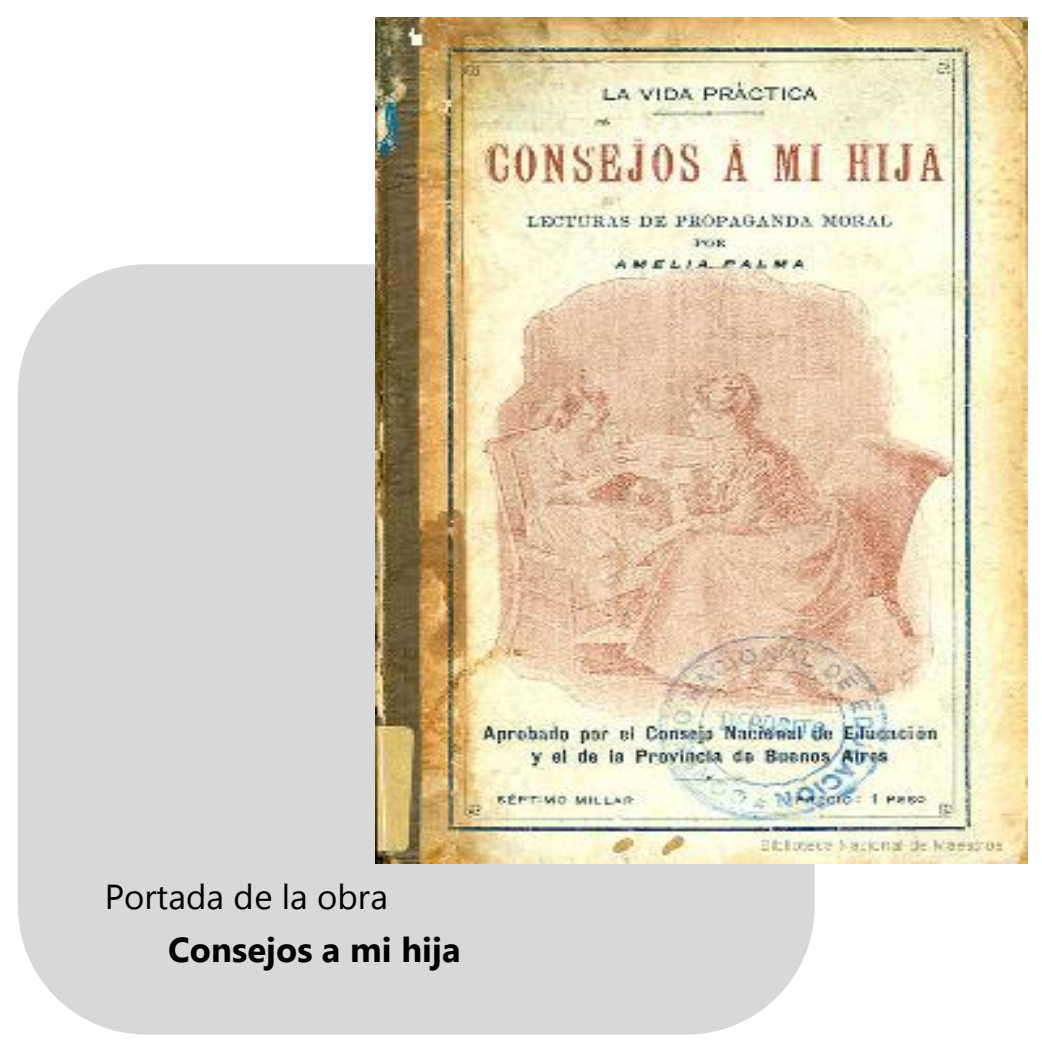

\section{Conclusiones}

Una de las paradojas señaladas por Joan Scott para la Revolución Francesa se erigió como una de las críticas más interesantes a la modernidad. La noción de ciudadanía se sustentó en la diferenciación genérica de los ciudadanos. Se invocó la igualdad universal a partir de la construcción de la diferencia, auspiciando una determinada identidad subjetiva por medio de lo cual se construyó lo "femenino" y lo "masculino".

Las contradicciones entre democracia y universalidad de los derechos se pueden fiscalizar en el proceso de modernización e invención de la Nación en la Argentina finisecular. La segregación de las mujeres de diversos aspectos de la vida social y política y la asignación de determinados mandatos basados en una supuesta naturaleza femenina se erigieron como una de las tantas incongruencias y contrasentidos del proceso de modernización.

Ahora bien, estas paradojas se reproducían en el naciente sistema de enseñanza. Este se modeló binariamente. Por ejemplo, las niñas debían aprender las nociones básicas de economía doméstica y labores manuales. Por su parte, los varones debían cultivar la fuerza, la destreza y la resistencia. La naturalización de los roles de género, 
esbozados por las maestras en la escuela primaria, se sustentó en un saber científico que promovía las desigualdades descriptas.

Los manuales escolares no fueron refractarios a estos condicionamientos genéricos promovidos por el Estado y asentados en las subjetividades de la sociedad civil. En el trabajo presentado avanzamos sobre los Consejos de Amalia a su hija Laura, como un paradigma de ese tipo de literatura pedagógica. Su autora es una maestra y no es casual su rol en esta trama. Es que ser maestra en el imaginario social representaba la extensión hogareña del rol maternal.

Los Consejos apelan a un marco normativo asociado a un conjunto de símbolos culturalmente disponibles que le asignan a la mujer un espacio de sumisión social con respecto al varón. Abnegación, altruismo y sufrimiento signan la relación de las mujeres y la sociedad. Estos tópicos son recurrentes en los Consejos de Amalia a su hija adolescente. Por lo tanto, ellas debían dedicarse a ser madres, maestras o, como máxima instancia, dedicarse a la caridad. Vemos aquí corporizado el apotegma de Scott en cuanto a que el género se define como un "elemento constitutivo de las relaciones sociales", que construyó una identidad subjetiva sobre el otro sexualizado.

Gracias a esta dimensión cultural, netamente varonil, la restricción a la participación política y los supuestos deberes de la urbanidad doméstica naturalizan en los Consejos, el rol de las niñas en la futura vida social. El modelo de mujer civilizada editorializada en la obra remite a la "buena ama de casa, culta y bondadosa". Hemos hipotetizado que con la obra señalada, el Estado proponía interpelar a las mujeres y niñas en un mandato social específico. Se buscaba contrarrestar los efectos nocivos que supuestamente acarreó la modernización de la Argentina. El aumento de la inmigración, el crecimiento urbano, la protesta y la polarización social eran peligros recurrentes en determinados discursos médicos, institucionales, pedagógicos y políticos de la época. Estas preocupaciones aparecen en el texto de Amalia. En esta dirección, los Consejos remiten solapadamente a defender un supuesto legado natural que pareciera peligrar ante los preceptos de la modernidad. Las mujeres eran las indicadas para sostener en el hogar una suficiente educación moral en relación con sus hijos. Así las cosas, pautar los deberes de las mujeres ayudaba a nutrir y regular la armonía social, desterrar las incertidumbres y la precariedad de la existencia, en un mundo amenazado por el creciente capital. 


\section{Bibliografía y fuentes}

Armus, D. (2007). La ciudad impura. Salud, tuberculosis y cultura en Buenos Aires. 1870-1950. Buenos Aires: Edhasa.

Adamovsky, E. (2009). Historia de la clase media argentina. Apogeo y decadencia de una ilusión. Buenos Aires, 1919-2003. Buenos Aires: Planeta.

Atkinson, F., Purón García J., Sellén, F. y Molina, E. (1912). Economía e higiene doméstica. New York: Apletton y Compañía.

Barrancos, D. (1996). Socialismo, higiene y profilaxis social, 1900-1930. En Mirta Zaida Lobato (editora). Política, médicos y enfermedades. Lecturas de Historia de la Salud en la Argentina. Buenos Aires: Biblos. Universidad Nacional de Mar del Plata. 117-149.

Bertoni, L. A. (2001). Patriota, cosmopolitas y nacionalistas. La construcción de la nacionalidad argentina a fines del siglo XIX. Buenos Aires: Fondo de Cultura Económica.

Cammarota, A. (2012). (en prensa). Juventud, género y educación en la mira del primer peronismo. En Biernat, C. y Ramacciotti, K. (compiladoras). Políticas sociales. Entre demandas y resistencias.Argentina.1930-1970. Buenos: Aires Biblos.

Cosse, I. (2006). Estigmas de nacimiento. Peronismo y orden familiar 1946-1955. Buenos Aires: Universidad de San Andrés- Fondo de Cultura Económica.

Dussel, I. (2000). La producción de la exclusión en el aula: una revisión de la escuela moderna en América Latina. Ponencia presentada en X Jornadas LOGSE. La escuela y sus agentes ante la exclusión social: Granada, España, 1-22.

-(2005) Cuando las apariencias no engañan: una historia comparada de los uniformes escolares en Argentina y Estados Unidos (siglo XIX-XX) en Pro-Posicoes, v. 16, n. $1,65-86$

Economía doméstica al alcance de las niñas, La escuela moderna. Serie elemental de instrucción primaria (1925). Buenos Aires: Cabaut y Cía. Editores, s/a.

Gagliano, R. (2003). Consideraciones sobre la adolescencia en el período. En Puiggrós, A. (dirección) y Carli, S. (coordinadora tomo VI). Discursos pedagógicos e imaginario social en el peronismo (1945-1955). Buenos Aires: Galerna, 175-203.

Guerrini, F. (1918). El ciudadano argentino. Nociones de instrucción cívica. De acuerdo con los programas de los grados $3 .^{\circ}, 4 .^{\circ}, 5^{\circ}$ y $6 .^{\circ}$ de las escuelas comunes. Buenos Aires: Colegio Cabaut y Cía., La Plata.

Gómez Rodriguez, A. (2005). Ciencias y valores en los estudios del cerebro. En Arbor. Ciencia, pensamiento y cultura, 479-492. Disponible en http: //arbor.revistas.csic.es

Lanciano de Pujolar, M. (1882). Tratado de corte para las escuelas de colegios y niñas. Buenos Aires: Imprenta y Librería Juan Bonet.

Lionetti, L. (2005). La función republicana de la escuela pública: la formación del ciudadano en la Argentina a fines del siglo XIX. En Revista Mexicana de Investigación educativa. Vol. X. No 27. 1225-1259. 
Lobato, M. Z. (2000). Entre la protección y la exclusión: Discurso maternal y protección de la mujer obrera, argentina 1890-1934. En Suriano, J. (Comp.). La Cuestión Social en Argentina, 1870-1943. Buenos Aires: Editorial La Colmena, 345-75.

(2007) Historia de las trabajadoras en la Argentina (1869-1960).

Buenos Aires: Edhasa.

López, S. y Vélez, B. E. (2001). La puesta en escena de la corporalidad femenina y masculina en la escuela urbana: linda como una muñeca y fuerte como un campeón. En Revista de Estudios de Género La Ventana. Vol. II. No 14. 83-101. Disponible en http://redalyc.uaemex.mx/src/inicio/ArtPdfRed.jsp?iCve $=88412394004$

Morgade, G. (2007). Burocracia educativa, trabajo docente y género: supervisoras que conducen poniendo el cuerpo. Educaçao \& Sociedade. Vol. 28, No 29, 400-425. Disponible en http://redalyc.uaemex.mx/src/inicio/ArtPdfRed.jsp?;Cve=87313705006.

Nari, M. (2005). Políticas de maternidad y maternalismo político. Buenos Aires, 18901940. Buenos Aires: Biblos.

Palacios, A. (1954). La Justicia Social. Buenos Aires: Claridad.

Palma, A. (1903). Consejos á mi hija. Lecturas de propaganda mora. Buenos Aires: Peuser. Versión disponible en http://www.bnm.me.gov.ar/ebooks/reader/reader.php?dir=00044062

Pita, V. (2012). Del consultorio al aula, del conventillo a la maternidad pública: algunos encuentros y desencuentros entre médicos y mujeres trabajadoras. Buenos Aires, 1890-1940. Ponencia presentada en Jornadas sobre cuerpos, pedagogías e instituciones educativas. Universidad Nacional de Quilmes. 1 de octubre.

Plotkin, M. (1994). Mañana es San Perón: Propaganda, rituales políticos y educación en el régimen peronista. Buenos Aires: Ariel.

Puiggrós, A. (1990). Sujetos, disciplina y curriculum en los orígenes del sistema educativo argentino (1885-1916). Buenos Aires: Galerna.

Queirolo, G. A. (2008). El mundo de las empleadas administrativas: perfiles laborales y carreras individuales (Buenos Aires, 1920-1940). Trabajos y Comunicaciones, No 34, 129-151. http://www.fuentesmemoria.fahce.unlp.edu.ar/art._revistas/pr.3727/pr.3727.pdf

Rocchi, F. (2000). Concentración de capital, concentración de mujeres. Industria y trabajo femenino Buenos Aires, 1890-1930. En Gil Lozano, F., Pita, V. e Ini, G. (Dir.). Historia de las mujeres en la Argentina, Siglo XX. Vol. 2. Buenos Aires: Taurus, 223-243

Scharagrodsky, P. (2006). Los ejercicios militares en la escuela argentina: Modelando cuerpos masculinos y patriotas a fines del siglo XIX. En Aisenstein, Á. y Scharagrodsky, P. Tras las huellas de la Educación Física Escolar Argentina. Cuerpo, género y pedagogía 1880-1950. Buenos Aires: Prometeo.

Scott, J. (1996). Only Paradoxes to offter. French feminists and the rights of man. Cambridge: Harvard University Press. 
-------- (1999). El género como una categoría útil para el análisis histórico. En Navarro, M. y Stimpson, C. (Comps.). Sexualidad, género y roles sexuales. México: Fondo de Cultura Económica. 265-302.

Valobra, A. M. (2008). Feminismo, sufragismo y mujeres en los partidos políticos en la Argentina de la primera mitad del siglo XX. En Amnis. Disponible en http://amnis.revues.org/666.

Valobra, A. M. y Ramacciotti, K. (2011). Modernas esculapios: acción política e inserción profesional, 1900-1950. En Estudios AHILA de Historia Latinoamericana 7. Asociación de Historiadores Latinoamericanistas Europeos. 23-52.

Wainermann, C. y Barck de Raijman, R. (1987). Sexismo en los libros de lectura de la escuela primaria. Buenos Aires: Ediciones del IDES.

y Heredia, M. (1999). ¿Mamá amasa la masa? Cien años en los libros de lectura de la escuela primaria. Buenos Aires: Editorial de Belgrano. 